\title{
Testability Modeling and Analysis of a Rocket Engine Test Stand
}

\author{
Gerald Temple, Nicholas Jize, Philip Wysocki \\ Nasa Ames Research Center \\ M/S 213-15, Moffett Field, Ca. 94035 \\ $650604-6445$ \\ (gtemple, njize, pwysocki)@mail.arc.nasa.gov
}

\begin{abstract}
This paper describes a testability analysis methodology that improves efficiency in maintainability and availability of a system, provides improvements in the overall capabilities of this system, and has historical verifiable data to compare the testability analysis metrics to the observed discrepancy reports. Here is a methodology that illustrates the use of a testability analysis tool to aid in the design and development of a health management system. Included is a brief discussion of how the model's testability output metrics can be used in conjunction with other types of model outputs for optimization purposes. Some top-level figures of merit are targeted here to verify that the testability analysis data is adequate and valid.
\end{abstract}

It is shown here that this technology can improve maintenance efficiency, and aid in automating an integrated vehicle health management (IVHM) system, while reducing the need for human interaction for decision making, data acquisition and testing. The technology identifies critical components in the system, and prescribes a fast and accurate failure detection and isolation method that diagnoses faults to the lowest level of ambiguity. The Safety, reliability and testability metrics identified here are used to reduce the test stand operator's stress levels by increasing the confidence in the operational state of the system, especially those related to critical components, before and during tests. Consequently, confidence in the test stand output data from the test article is realized. It is proven here that this technology also adds confidence in sustainability improvement of the test stand, which is above and beyond meeting just performance specifications. False alarms and false replacement concerns are also addressed here.

The importance of using today's testability analysis tools for assessing and optimizing integrated vehicle health management systems is emphasized in this paper. With this technology we were able to model a rocket engine test stand and utilize the existing test stand sensors as a baseline for the testability analysis. We used the observed discrepancy maintenance reports provided by the test stand engineers to assign failure modes to the components. ${ }^{12}$

\footnotetext{
${ }^{1}$ U.S. Government work not protected by U.S. copyright.

${ }^{2}$ IEEEAC paper \#1127, Version 4, Updated December 13, 2004
}

TABLE OF CONTENTS

\author{
1. INTRODUCTION \\ 2. TeSt StANd And Model Description \\ 3. The Modeling Process And ObJectives \\ 4. Testability Metrics And Results \\ 5. Conclusions \\ 6. ACRONYMS AND ABbREVIATIONS \\ 7. REFERENCES \\ 8. ACKNOWLEDGMENTS \\ 9. BIOGRAPHY
}

\section{INTRODUCTION}

In support of the IVHM Analysis and Optimization (A/O) work done at NASA-Ames, a testability analysis tool was used to develop a diagnostic model of the vehicle hardware. With the diagnostic model, it was shown here that these testability tools are useful design tools, and that they should be an integral and necessary part of an IVHM system analysis and optimization by verifying and validating the testability outputs. In order to do this, it is best to have some real historical data to compare the testability metrics with. Using the results from these comparisons can help build better testability models and strategies, as well as allow a variety of trade studies for future technology developments.

The Stennis rocket engine test stand was chosen because there is an extensive amount of historical test data available to define a solid baseline model of the test stand. In addition, because rocket engine testing and retrieving of test data with this test stand resembles a launch operation focused on the propulsion system. Since flight systems are tested at this facility, this offers a great opportunity to capitalize on the reality that ground and flight systems are integrated testable systems. This test stand can be established as a permanent site to test new health management elements such as intelligent sensors, intelligent components and integrated health management architectures. Better testability models and strategies, as well as allow a variety of trade studies for future technology developments Adding new sensors or making modifications is much less complicated on this test stand than in the case of flight hardware, making this an excellent test bed for testability verification and validation. 
This paper captures the testability modeling effort at NASA Ames Research Center on the fluid flow system of the test stand and it is used to verify the validity of using testability analysis.

Although the testability technology offers great opportunities for advancement in health management and improvements in systems optimization techniques, it is far from perfect. There are a number of concerns and gaps that need to be addressed when using this methodology. A plan for model development with targeted reviews of model accuracy that includes domain expert knowledge and input is essential.

\section{TEST STAND FACILITY AND MODEL DESCRIPTION}

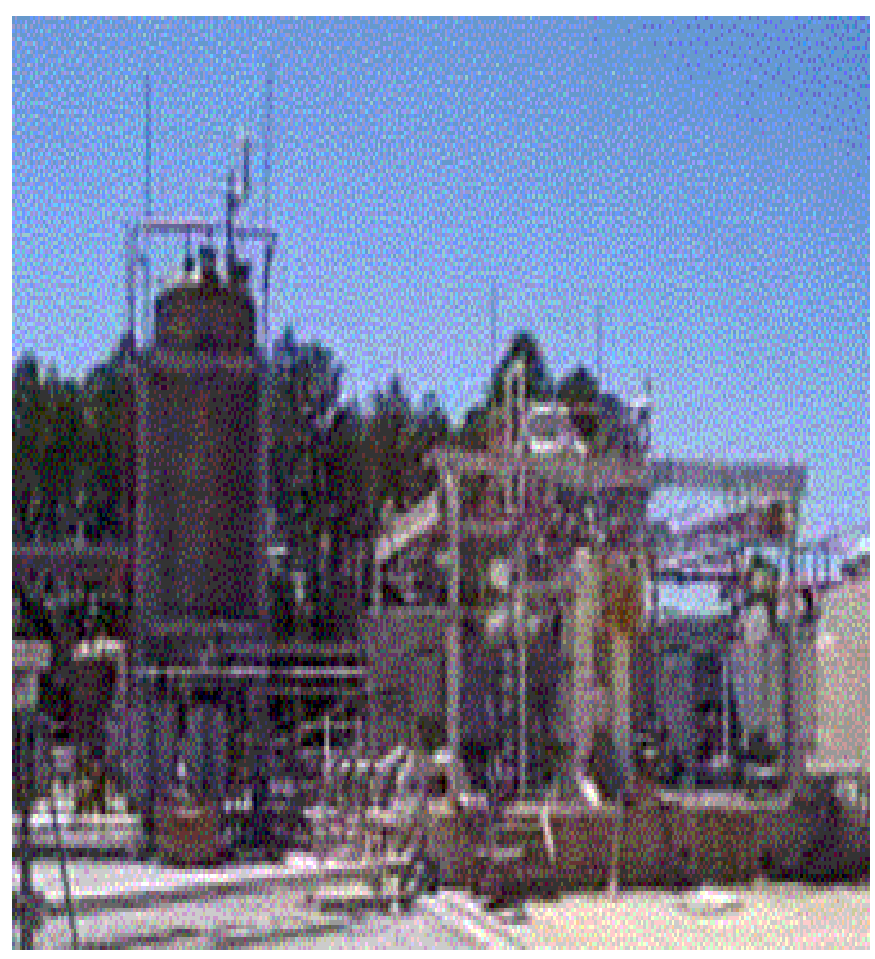

Fig.1 E2 Cell 1 Test Stand

The E-2 test facility, formerly known as the High Heat Flux Facility (HHFF), was originally constructed to support materials development testing for the National Aerospace Plane (NASP) by subjecting special test articles to extreme e temperature conditions. Recent test projects at E-2 have included composite cryogenic tanks, turbo-pumps, and preburners. The facility is now being modified to support advanced component and engine development projects. The facility has two test cells capable of accommodating multiple programs at the same time

The modeling process began in April 2004, after our first meeting with the domain experts to be sure that we had a clear understanding of the piping and instrumentation drawings (P\&ID)s and the accompanying Test Facilities Capability Handbook (TFCH). We completed $95 \%$ of the model by mid July. Since then we have been refining the test stand model to be certain that it is a good representation of the testability characteristics of the test stand itself. This was fairly tricky, because we decided to include external failure modes that were observed visually or aurally by operators, maintenance technicians, and inspectors as sensory tests in our testability model. After reading the discrepancy reports that provide information on how failures were discovered, we felt that this was a realistic test (manual inspection tests) that should be added to our diagnostic model.

Cell 1 is an open-air covered test cell equipped with a 2 ton Jib crane. A structural blast wall separates the supporting test complex infrastructure from the test cell. Gaseous propellant run, storage and transfer systems are available. A Pebble Bed Heater provides a hot-gas capability. The facility also includes a Signal Conditioning Building (SCB) and an Electrical Equipment Building (EEB). All data acquisition and control aspects are fully functional and are supported by the E-2 TCC, located within the Test Operations Building (TOB).

Cell 1 is a $20 \mathrm{ft}$. by $20 \mathrm{ft}$. covered test cell. It can withstand up to $100,000 \mathrm{lbf}$ of thrust from a combustion device or turbo-pump. It has the capability of providing the test article with LOX, LN2, LH2, RP-1, water, GH2, GOX, and GN2. The facility is equipped with an ablative coated concrete pad located east of the test cell and is capable of withstanding the pressure and heat loads generated by a 100,000 lbs thrust class combustion device. Spray nozzles supplied with water from the deluge water system are there to reduce the temperature of the impingement area cover of the pad. The location and size of the concrete pad can accommodate combustion devices mounted at the top of the test article support stand (120 inches from the floor of the cell) and canted downward at up to a 10 degree angle from the horizontal.

The methodology described is independent of a specific tool. We used the Qualtech Systems (QSI) TEAMS diagnostic tool to develop the Stennis E2 Cell 1 Test Stand testability model shown below in Fig. 2. 


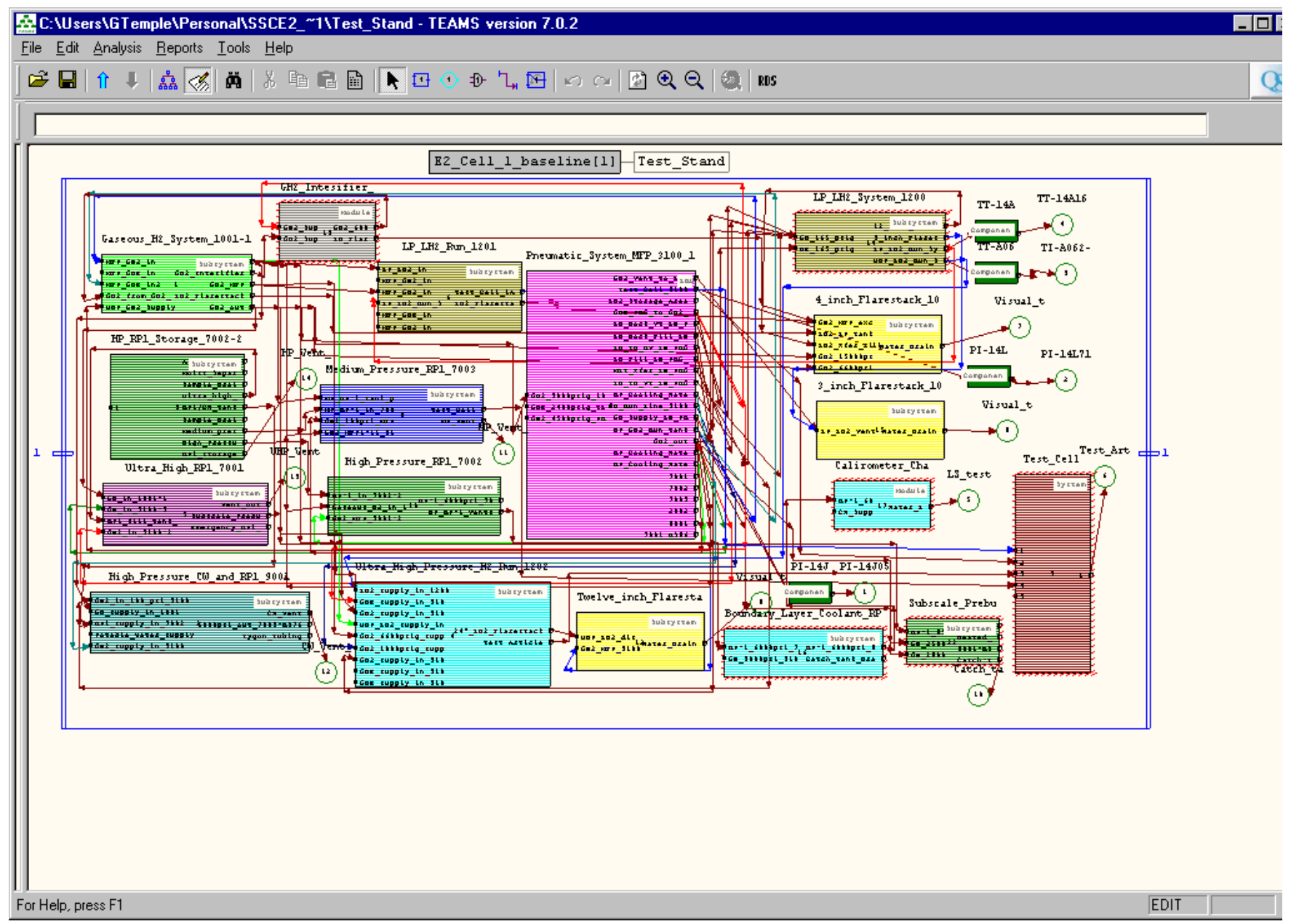

Fig.2 Test Stand Testability Model

The above is the complete model of the test stand without the LOX tanks. The different levels of subsystem hierarchy are not seen in this top-level model however. The modules with red cross hatches around the perimeter have no lower levels of model hierarchy. We felt that some subsystems of the test stand were not critical enough for us to spend the time modeling them. In other cases, such as the GH Intensifier subsystem, we simply did not have the drawings available. We never received the LOX tank piping and instrumentation drawings (P\&ID). Therefore we could not add the LOX configurations to our model. We did determine that we had enough information with the gas flow drawings provided to adequately address our objectives and goals, which was to verify the validity of a testability model with respect to a real operating test stand by comparing the concomitant test stand historical data and testability metrics generated from the model.

We used the Detex (DSI) eXpress diagnostic testability tool to develop this E2 Cell 1 Test Stand simplified block diagram schematic seen in Fig. 3 (next page) $n$ It shows the propellant system, the run tank pressurization system and the commodity storage capability configuration for test stand E2 Cell 1. 


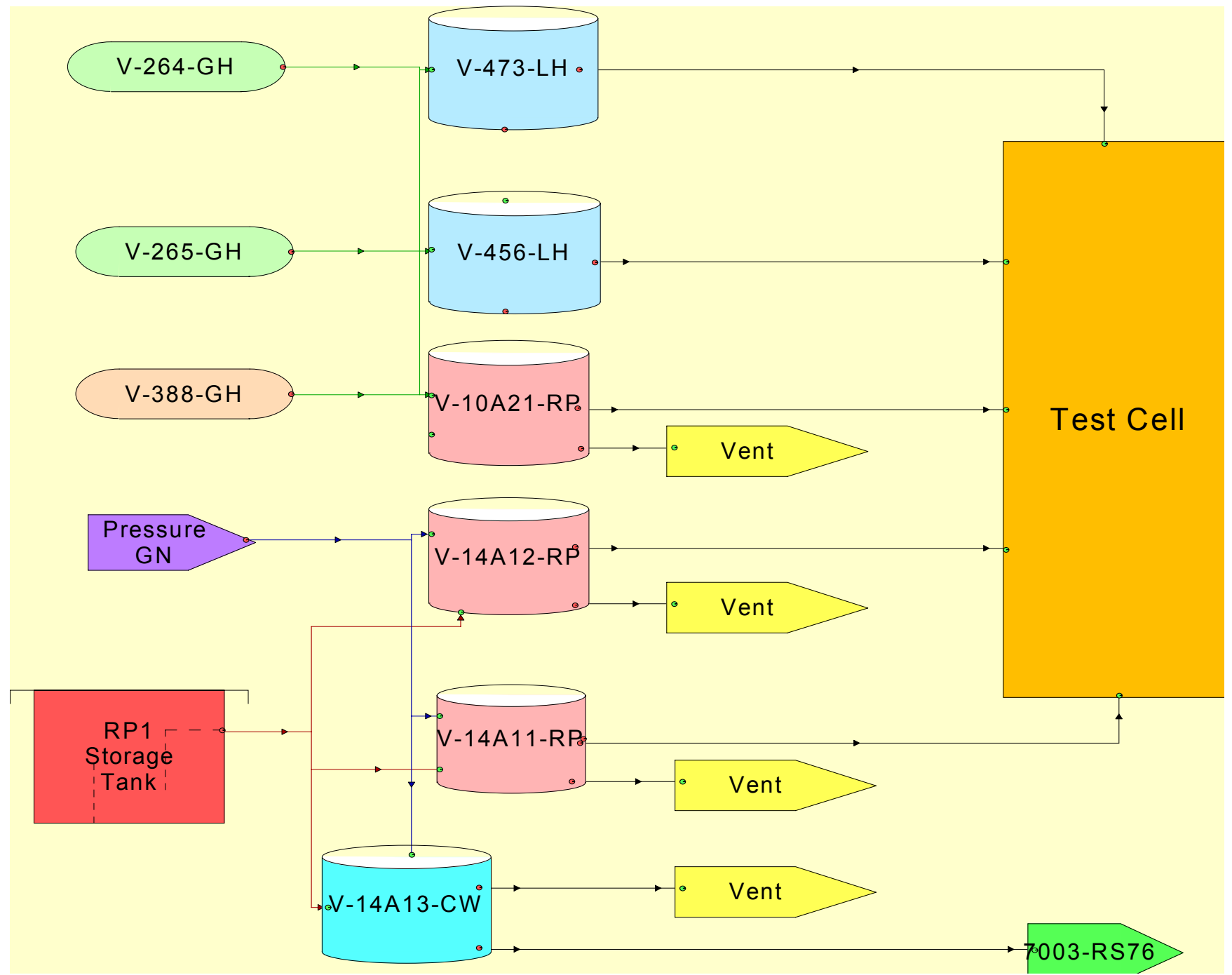

Fig.3 Configuration for Test Stand E2 Cell 1

- Cell 1 has an intensifier (level 2 clean) for the purpose of pressurizing the GH2 vessels (V-264-GH, V-265$\mathrm{GH}$, and $\mathrm{V}-14 \mathrm{~A} 18-\mathrm{GH})$ up to 6,600 psi with either GN2 or GH2. The intensifier can charge one vessel from sitewide average 3,000 psig to 6,600 psig in approximately 8 hours. The Cell 1 Ultra High Pressure vessels for GH2/GN2 (V-14A18-GH, 15,000 psi/625 ft3 level 2 clean) are rechargeable from the site-wide average 3,000 psig to 15,000 psig in 12 hours. This is accomplished using the E-1 facility UHP system and a cross-country line between E-1 and E-2. Cell 1 is equipped with a flarestack capable of burning test article $\mathrm{GH} 2$ discharges.

\section{Gaseous Hydrogen (GH2)}




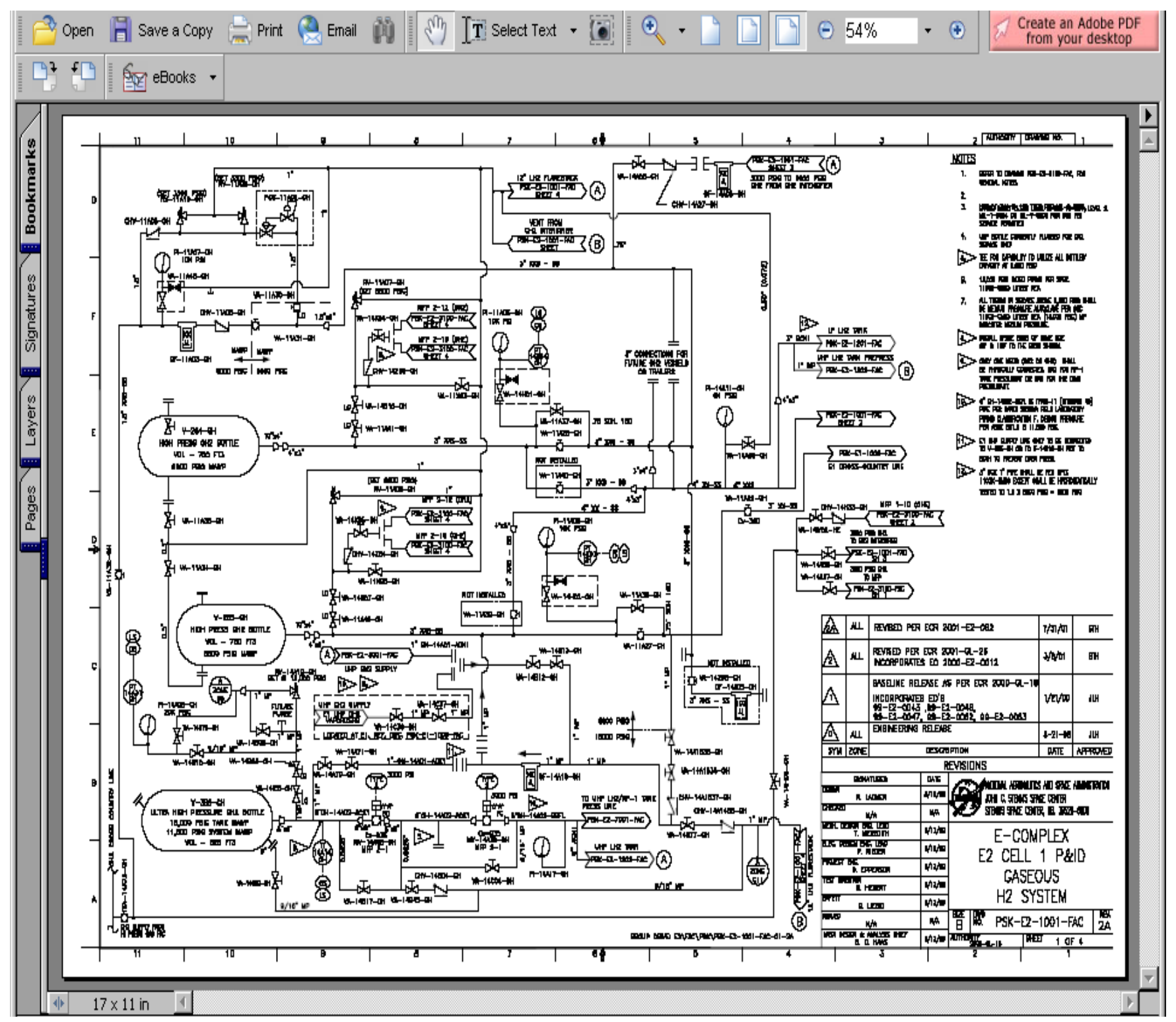

Fig.4 The Gas Storage and Distribution P\&ID Used to Develop the Testability Model in Fig. 5 


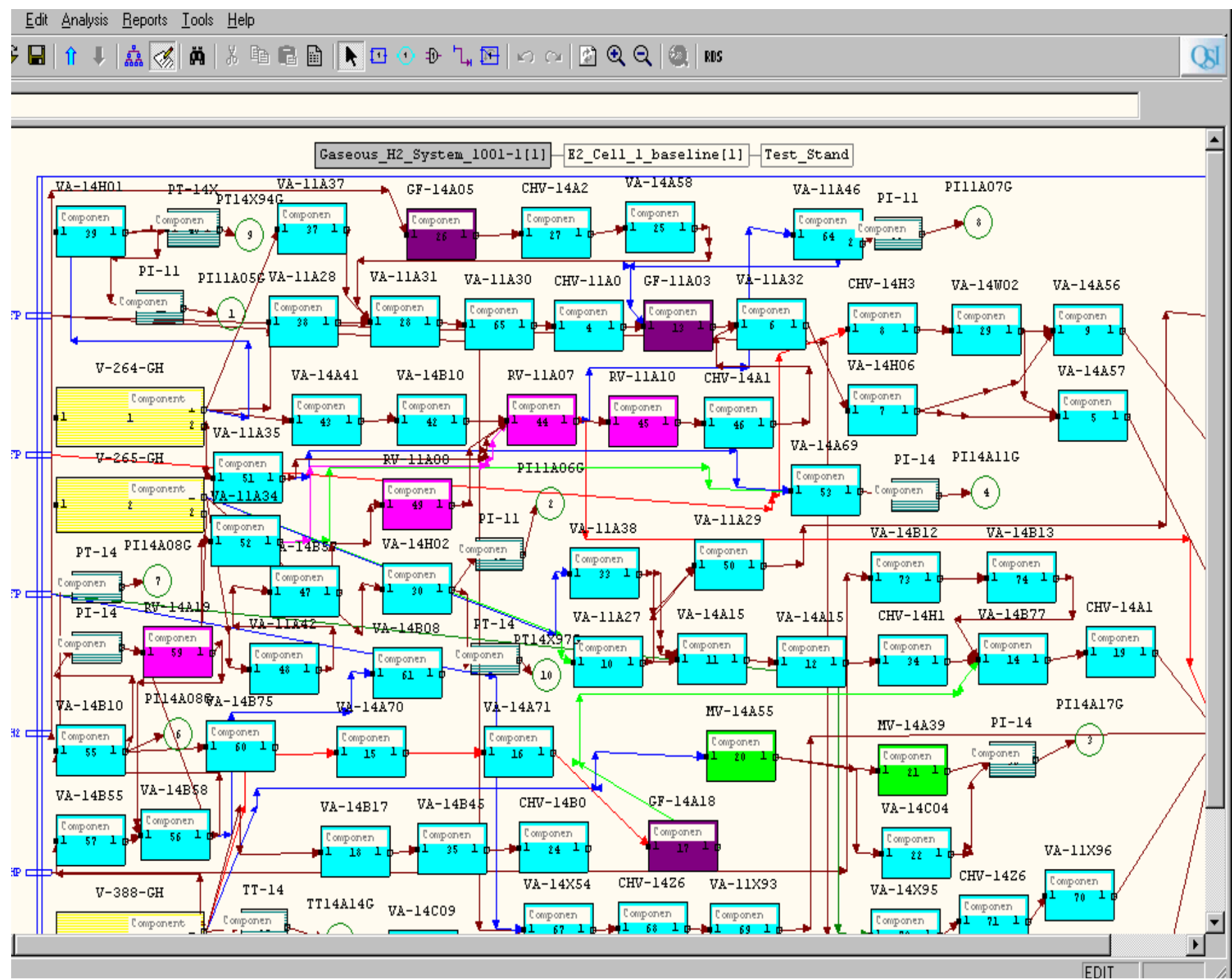

Fig.5 Gas Storage and Distribution Testability Model

\section{Liquid Nitrogen (LN2)}

- $\quad$ LN2 is not currently available at E2 Cell 1.

\section{Gaseous Nitrogen (GN2)}

- The E-2 Ultra High Pressure vessels for GH2/GN2 (V14A18-GH, 15,000 psi/625 ft3 level 2 clean) and GN2 (V-10A09-GN, 15,000 psi/247 ft3 level 1 clean) are rechargeable from the site-wide average $3,000 \mathrm{psig}$ to 15,000 psig in 12 hours. This is accomplished using the E-1 facility UHP system and a cross-country line

- between E-1 and E-2. A 6,000 psi/6 GPM LOX pump (P-14Q36-LO), supplied by LOX vessel V-14A01-LO, can be used in LN2 service to charge the GN2 vessels (V-142-GN and V-145-GN) from site-wide average 3,000 psig to 5,667 psig in 9 hours or vessel V-10A09GN to 6,000 psig in approximately 3 hours.

\section{Gaseous Helium Supply (GHe) Model}

- $\quad$ Site wide GHe supply is available at E-2 up to 4,400 psig. 
Cell 1 is equipped with a flare stack capable of burning test article $\mathrm{GH} 2$ discharges as depicted in this P\&ID in

Fig.6.

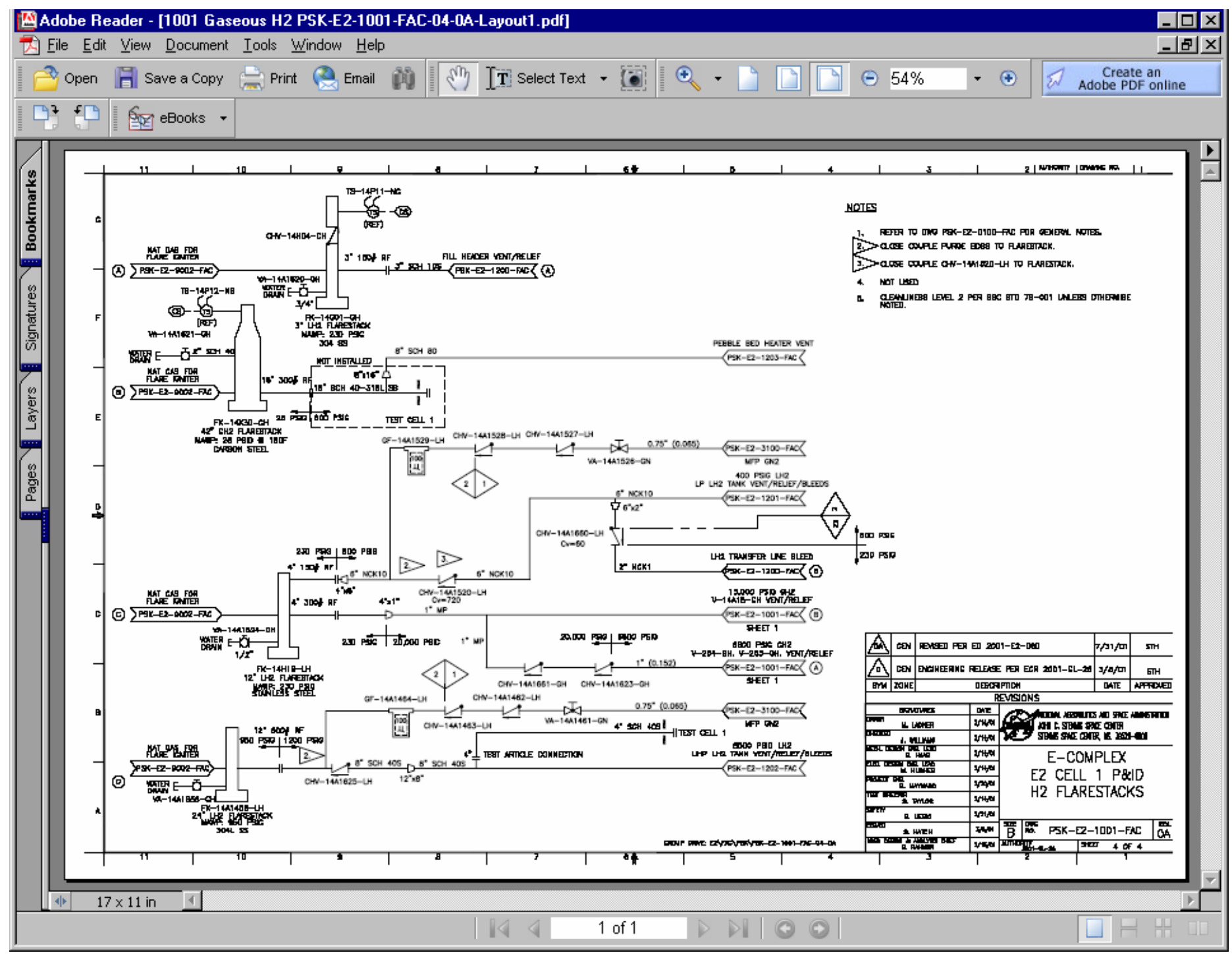

Fig.6 GH2 Discharge Flare Stack P\&ID Used to Develop the Testability Model in Fig. 9 
Cell 1 has an RP-1 discharge line routed to a waste tank at the north side of the test cell blast wall, depicted in this
Rocket Propellant (RP-1) Storage Testability Model in Fig. 7 below.

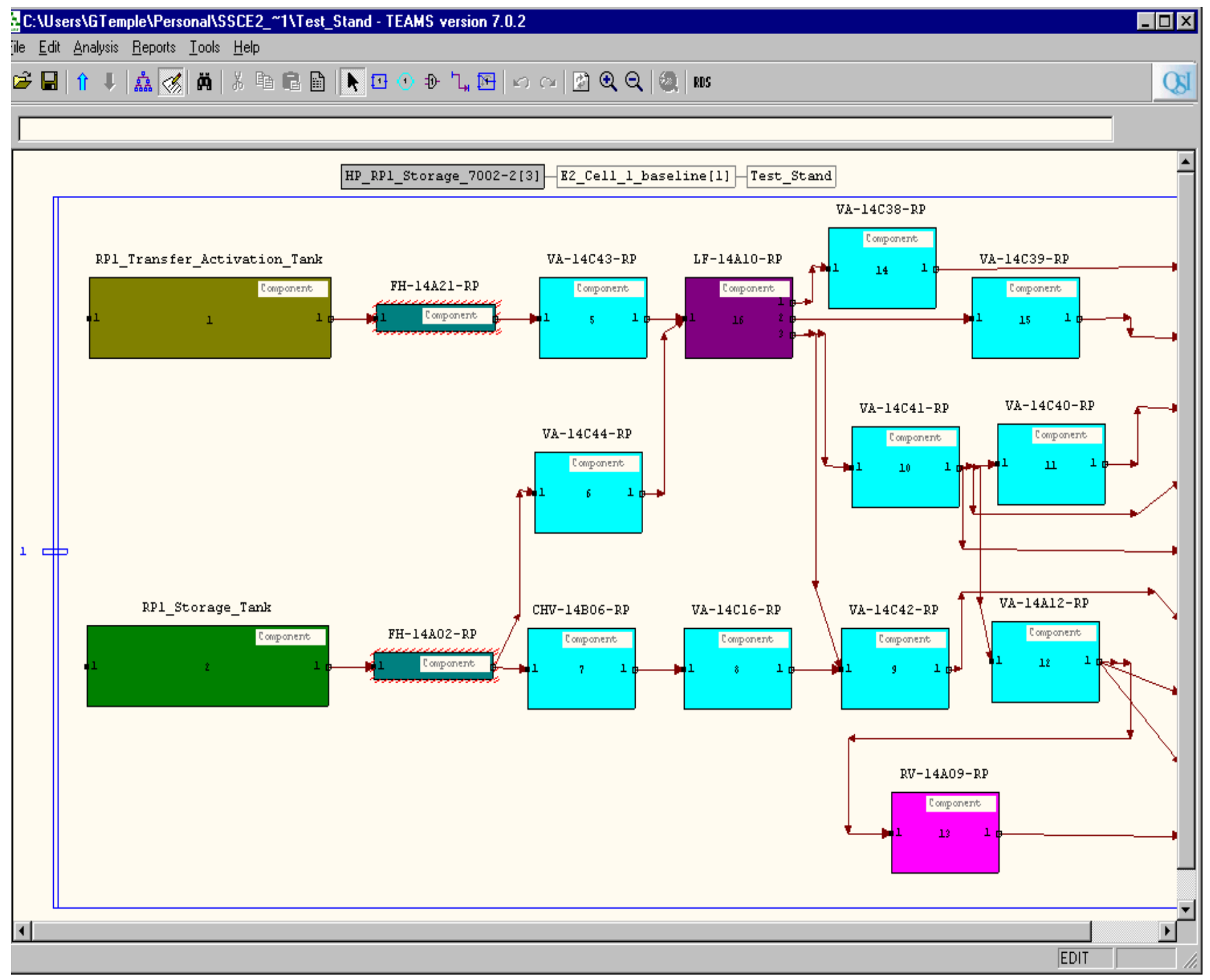

Fig.7 Rocket Propellant (RP-1) Storage Testability Model 


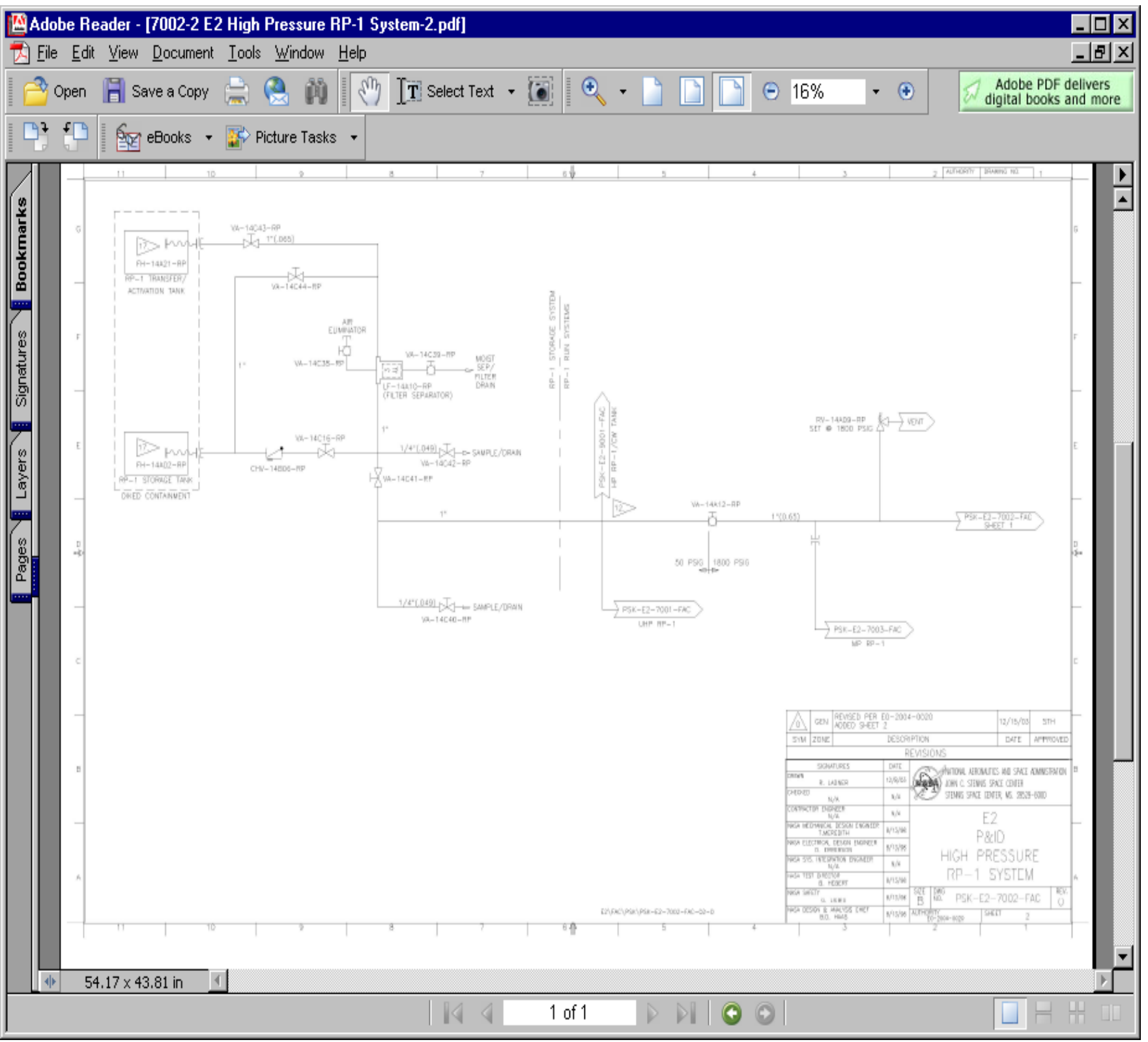

Fig.8 Rocket Propellant (RP-1) Storage P\&ID Used to Develop the Storage Testability Model in Fig. 7

Electrical System Capabilities (Not in the Testability Model) The sensors, transducers, and instrumentation are modeled as testability test points. The following sections briefly describe the control system, instrumentation, Low Speed and High Speed DAS systems, data processing, communications, power and video systems.

\section{Control System (CS)}

The facility control system handles the transfer of propellants to storage and run tanks, operation of pumps and vaporizers, and pressurization of run tanks. Facility alarms for out of tolerance conditions are provided. The facility controls provide a real-time display of operations in a process format. A test article control system contains a general automatic sequencer that can be configured for a test article specific test sequence. The system provides (via patching from the respective DAS signal conditioners) the ability to connect sixty-four (64) analogs redline monitoring and shutdown (cutoff) measurements to the Programmable Logic Controller (PLC). Of these 64 channels, up to sixteen (16) measurements may be High Speed Instruments, such as accelerometers or speed sensors.

A PLC is also used for run tank pressurization, temperature ramping, and valve sequencing. This PLC can be used for analog outputs of up to sixty-four (64) STE and/or Test Article devices of which thirty-two (32) can control hydraulic servo valves. A hardwired Emergency Shutdown System is provided that manually overrides the control systems and shuts down the facility and associated test article systems in a predetermined timed sequence. 
Facility instrumentation is installed for real-time display of facility processes and data recording. Instrumentation provided for the test article will be determined with each customer. The facility provides the ability to display realtime article measurements.

The instrumentation for fluid flow is shown below in Fig. 9, modeled in green. The flare stacks are yellow.

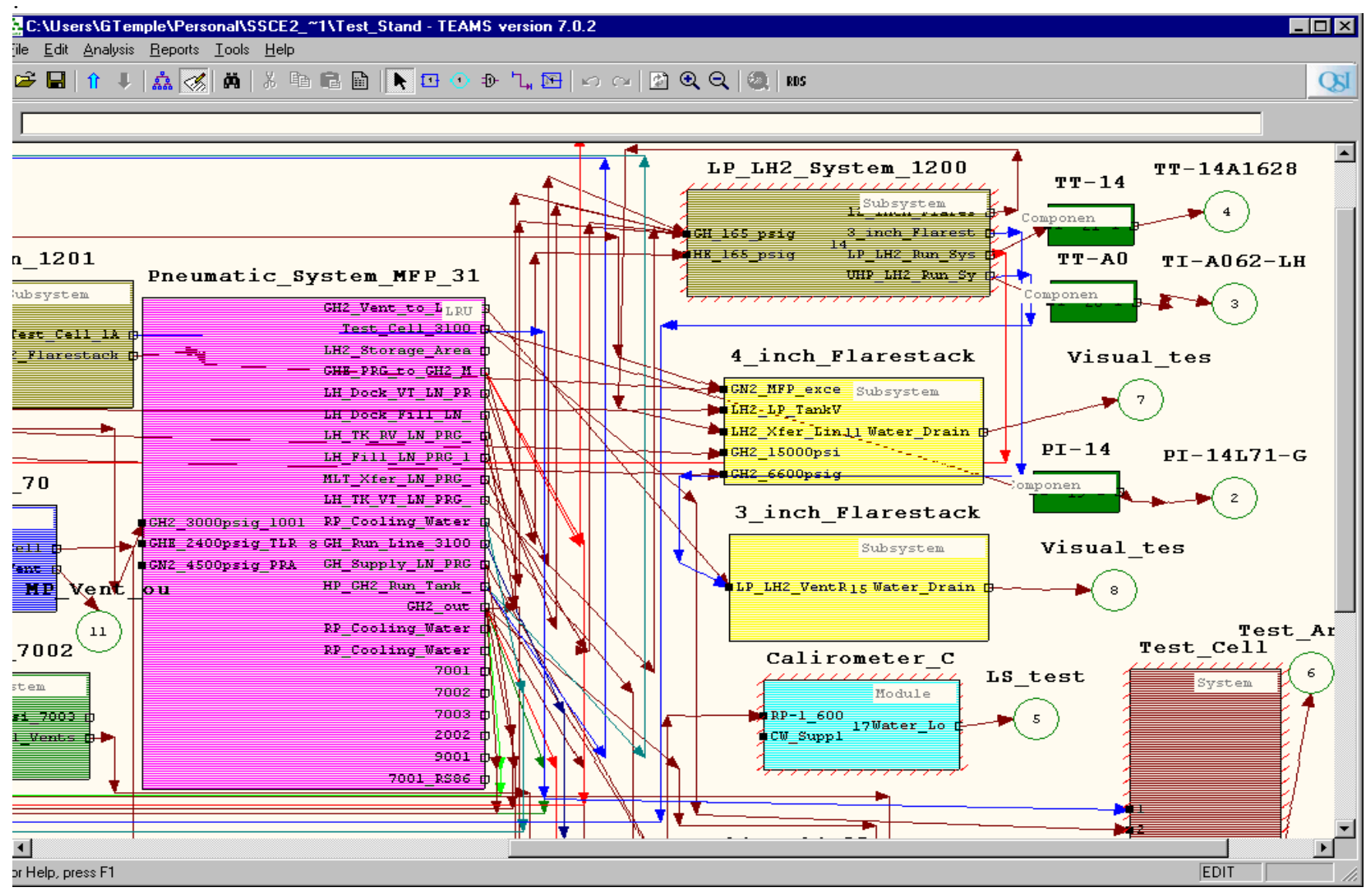

Fig.9 Model Depicting Instrumentation for Fluid Flow

Measurements that provide test article response information, and time critical control functions are located at facility to test article interfaces, have a $5 \mathrm{~ms}$ response, except sheathed thermocouples, which have a $250 \mathrm{~ms}$ response and RTDs which have a $500 \mathrm{~ms}$ response.

\section{Low Speed (LS) Data Acquisition System}

The Low Speed Data Acquisition System (LSDAS) provides 360 channels with a total throughput of $200 \mathrm{KSPS}$ of 16 bit data. Test Article and Control system data are recorded on the LSDAS. IRIG $B$ is also recorded on the LSDAS for time correlation between systems. The DAS end-to-end uncertainty is $+0.15 \%$, excluding instrument and associated cabling. The LSDAS provides a real-time tabular display with an updating rate of 3 sps per measurement and redundant data recording. A limited number of real-time calculated values are available, depending on complexity and available LSDAS overhead.

\section{High Speed Data Acquisition System}

The High Speed DAS (HSDAS) throughput is 50 KSPS per channel at 16 bits for 64 channels. The data is recorded on Super VHS tape along with IRIG B for time correlation. Discrete event channels are also available.

\section{Data Processing}

Data processing is provided for both the LSDAS and the HSDAS. The LSDAS data is converted to Engineering Units and processed into the E-complex standard file format. The LSDAS data file can be provided in an ASCII format. A measurement and calculated values plotting program is available. A quick look program is also available for on-line analysis. Data backup is provided on DAT or CD ROM. 
The HSDAS data is generally filtered and sub-sampled to $5 \mathrm{KHz}$ and processed to compute FFT for frequency analysis. A quick look dynamic analysis program is available for data reports. Data backup is provided on CD ROM for FFT data and SVHS for raw dynamic data. Post test, off-site data transfer is available for both data systems through the Internet. Data security is provided through password protection.

\section{Communications}

The facility communications system has the capability to provide communications between the Test Control Center and the test cell.

\section{Power}

AC - The facility power system provides 480VAC, 220VAC, 208VAC, and 110VAC; single and three-phase.

DC - The facility power system provides $28 \mathrm{~V}$ DC for valve control.

\section{Video Systems}

A standard VHS video system (30 frames/sec) is available for test article and facility monitoring.

Video displays/recorders are provided in the test control room. Cell 1 has a three-position high-speed video system used for test article monitoring and recording. Currently video cameras are provided on an as available basis, with video mounts and cabling as part of the E-2 facility. Future upgrades will provide dedicated high-speed video cameras.

\section{Ancillary Facility Systems}

The following sections describe the test article support stand, hydraulics system, plume impingement area and deflector, deluge system and communications.

\section{Test Article Support Stand}

The E-2 Cell 1 test article support stand is designed to support a test article weighing up to 3,000 lbs and generates up to $100,000 \mathrm{lbs}$ of thrust (200,000 lbs impulse load). The orientation of the support stand has the test article plume directed eastward from the test cell. The support stand is designed such that the test article centerline can be mounted from 60 to 120 inches off the test cell floor (the test cell floor is 30 inches below the grating). The test stand is capable of mounting a combustion device at up to a 10degree downward angle from the horizontal and is capable of taking side loads of up to $15,000 \mathrm{lbs}$. The stand is equipped with an axial direction thrust measurement system with accuracy of 0.5 percent of load over the thrust range of 10,000 to $100,000 \mathrm{lbs}$.

\section{Hydraulics System}

The facility includes a hydraulic system for actuating facility and STE hydraulic valves. The system at Cell 1 is capable of generating 3,000 psig and 40 GPM with a 150gallon hydraulic fluid reservoir.

\section{TEA/TEB Ignition System}

Cell 1 is equipped with a Triethyl-Aluminum (TEA) and Triethyl-Borane (TEB) combustion device ignition system.

\section{Deluge System}

The facility has a 4,000 GPM deluge system for the purpose of limiting damage in the event of a test stand fire. The deluge system water supply is only available when E-1 is not involved in a test requiring deluge support. The Cell 1 Deluge System covers the following areas: The Test Cell, all active LOX vessels, all active LH2 vessels, all active RP1 vessels, all active GOX vessels, the Pebble Bed Heater, all active tanker fill headers, and the hydraulics skid. The deluge nozzles covering the tanker fill headers are controllable both remotely and locally whereas all other areas are only remotely operated from the control room.

\section{Fire and Gas Detect System}

The E2 Test Complex employs a fire and gas detection system with a display within the E2 Test Control Center (TCC) that is independent of the Facility and Test Article Control System. This fire and gas detect system provides operators within the (TCC) visibility into severity and location of fires and Gaseous Hydrogen leaks.

\section{Pebble Bed Heater}

A Pebble Bed Heater provides a hot hydrogen capability. This system has been installed and partially activated, awaiting a customer need.

\section{THE MODELING PROCESS AND OBJECTIVES}

Before attempting to develop the model, a strategy for setting up the model according to the actual schematics of the test stand was developed. This required the modeler to have a great deal of knowledge about how the test stand functions, the test stand outputs, and the modeling objectives. An understanding of test stand functionality was absolutely essential prior to developing the testability model. Initially, the test stand model fidelity or level of hierarchy was also decided upon for producing an adequate representation of the actual system and accomplishing the intended goals of the model. Failure modes along with failure rate data from handbooks were added to the various components and modules that closely resemble the operational failures and effects experienced by the system users. Choosing the test stand operating modes, such as the fill tanks mode and the fuel feed to the engine running mode, and having the flexibility to change to different operational modes and phases, using the same test stand model, was essential to meet the objectives of the testability analysis. Also, to accomplish an effectively useful test stand testability model, the proper signals and functions that propagate throughout the test stand were defined; these were identified as temperature and pressure. The choice of which components are needed for model development, as well as which components are critical to the system operation, required input from test stand experts. 
An important part of the modeling strategy was the decision to model only tanks, valves, filters, transducers (sensors) and instrumentation, because they were found to be the components that failed most often, and were deemed the most critical to test stand operations. Also, because testability analysis is based on the schematic, binary (pass, fail) tests (sensors, transducers, and instrumentation) placement, and signal dependency, the modelers had periodic discussions with the test stand operators and designers to determine if the model was functioning similarly to the actual test stand behavior, from a testability perspective (not a performance perspective) and if the analysis tool was providing diagnostic metrics that are useful perspective (not a performance perspective) and if the analysis tool was providing diagnostic metrics that are useful.There are other operating modes that are not modeled for discussion here, such as the test conditions set up mode with fuel not going to engines or tanks.
The accuracy of the analysis is dependent on the accuracy of the model. The model accuracy is dependent upon the modeler's understanding of the system and interpretation of the drawings. Another factor that limits the model accuracy is the testability tool's limitations (e.g., direction of fluid flow). For an accurate representation of the model, a number of assumptions were identified prior to model development and continued through out the test stand model development process. The assumptions added were based on the limitations of the software to perform functional flow direction in a fluid system, such as the Stennis E2 Cell 1 Test Stand. As seen in the high Pressure RP1 subsystem model below in Fig. 10, switches were added near the tank vessel to accurately reflect the correct fuel flow direction to a particular operating mode that was similar to fuel flow in the P\&ID. The switches added had no other effects on the simulation analysis results.

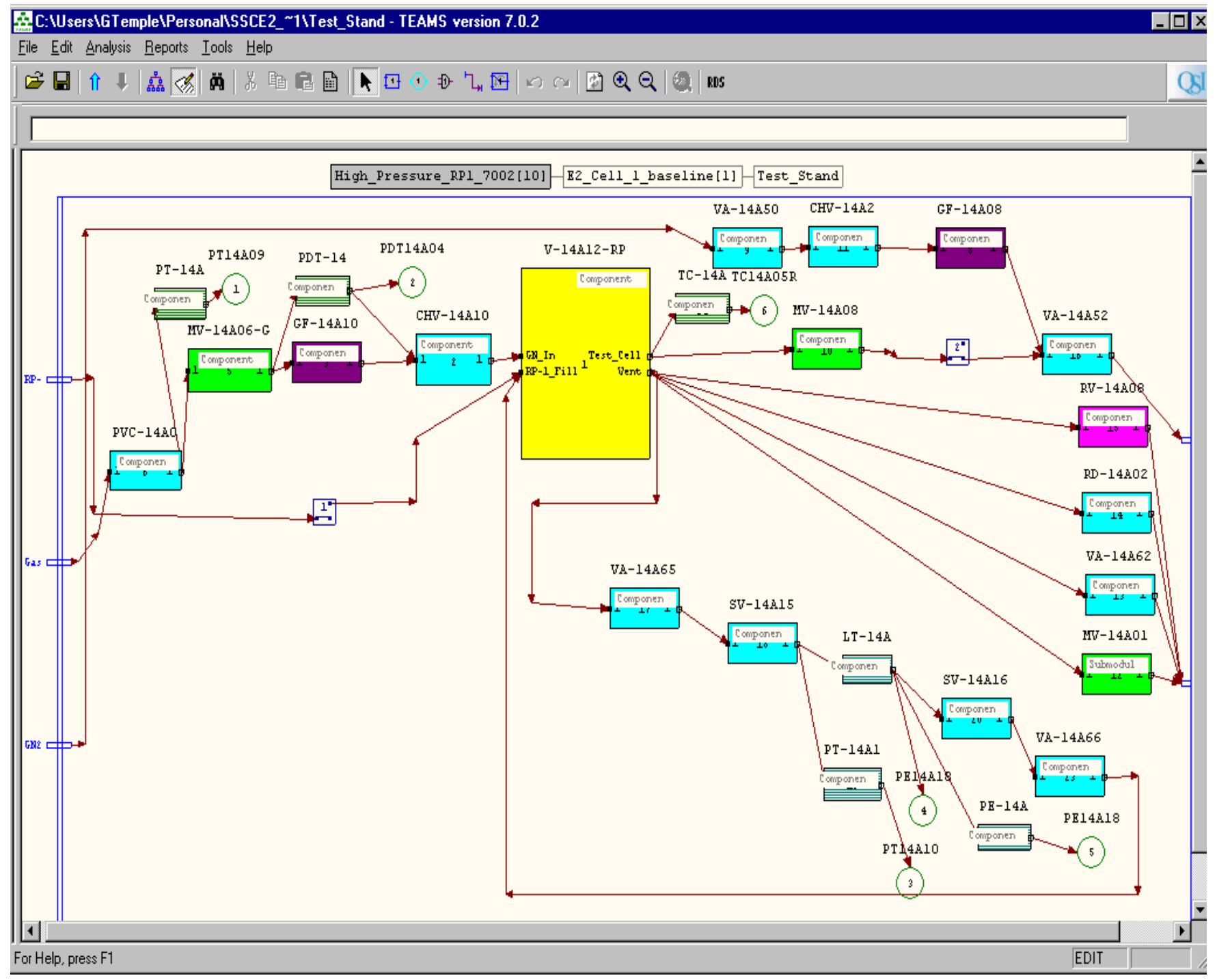

Fig.10 High Pressure RP1 Subsystem Model 
The P\&ID in Fig. 11 below shows the actual flow from which the model was comprised

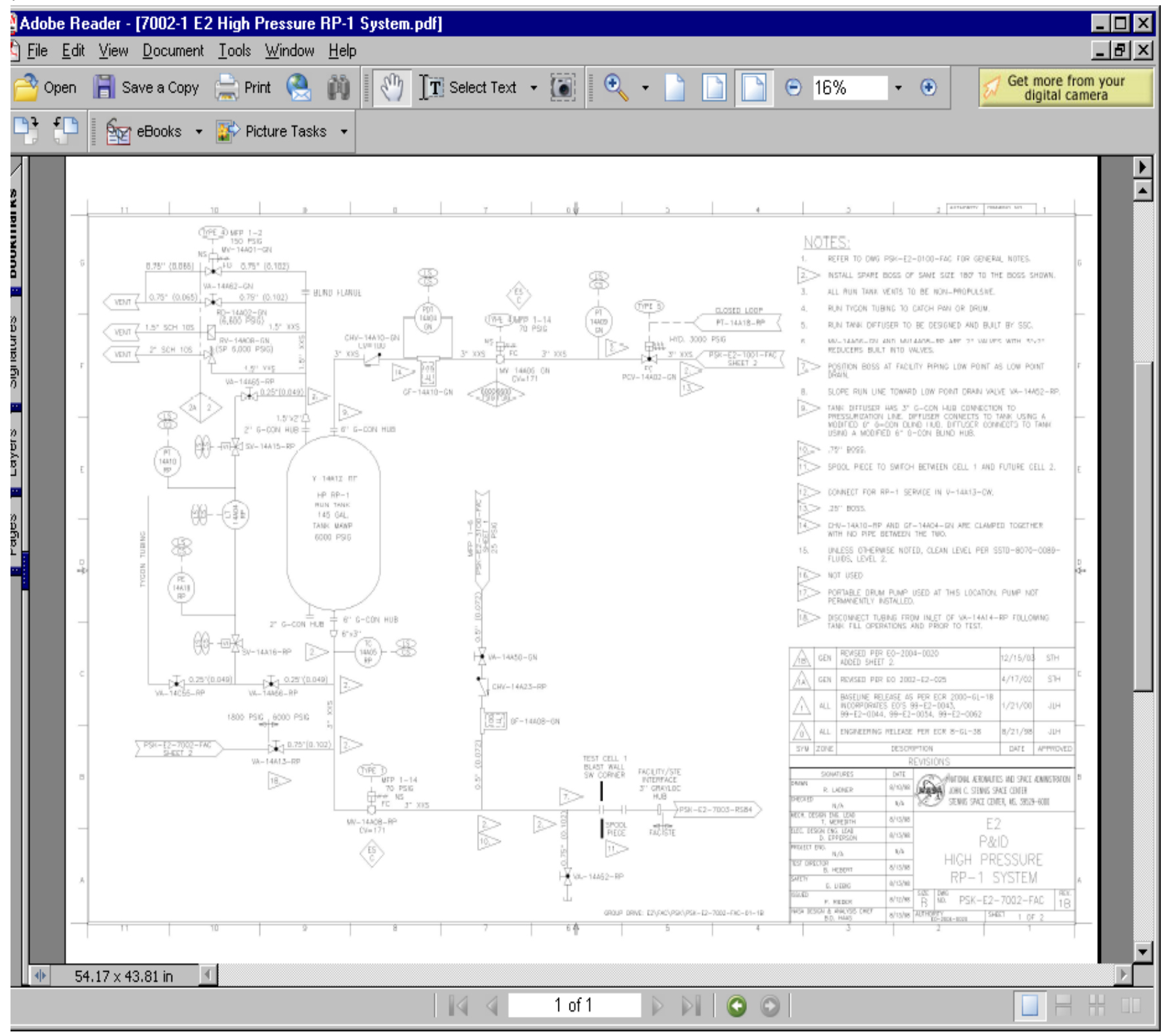

Fig,11 High Pressure RP1 Subsystem P\&ID 
The TEAMS switch property control panel window here in Fig. 12 is allowing the specification of a switch, viz., the switch position, an operating mode for the test stand. In the panel, the run test mode, feeding fuel to the rocket engine, is being specified

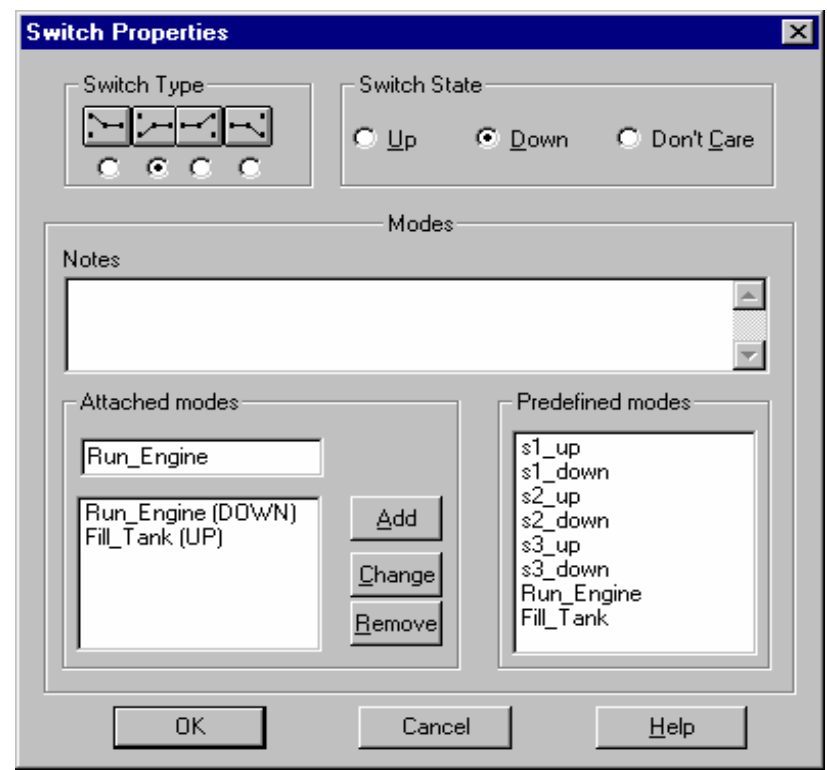

Fig.12 TEAMS Switch Property Control Pane

The TEAMS switch property control panel window for the same switch is shown below in Fig. 13 allowing filling tanks operating mode, and not allowing feeding fuel to the rocket engine operational mode

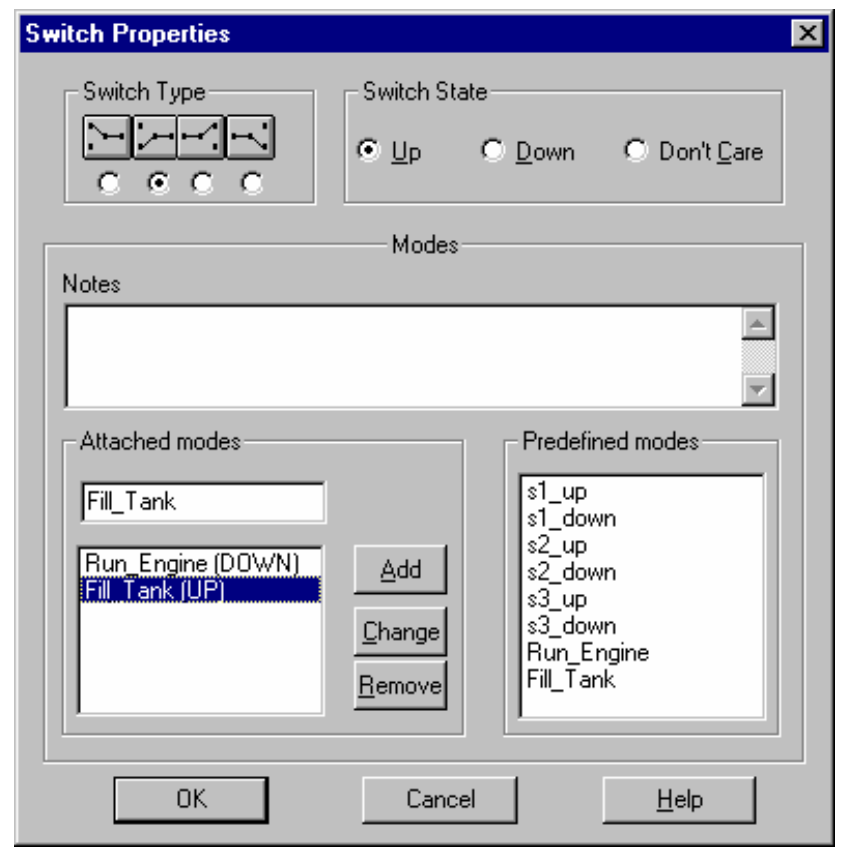

Fig. 13 TEAMS Switch Property Control Panel
The test stand model is hierarchical and the modules at various levels can be given labels (e.g., system, subsystem, component, failure mode, etc.). As such, the tool allows testability analysis to be performed at a functional failure mode level (failure modes) or a component analysis modules at component level) as shown below in Fig. 14. The model can also be run at the failure modes level for determining the MTTF for the test stand, as well as for various subsystems. Of course there were no test instruments on most of the components, so the failure isolation at component (isolation) level was poor (large ambiguity group size), even though the probability of failure detection was good

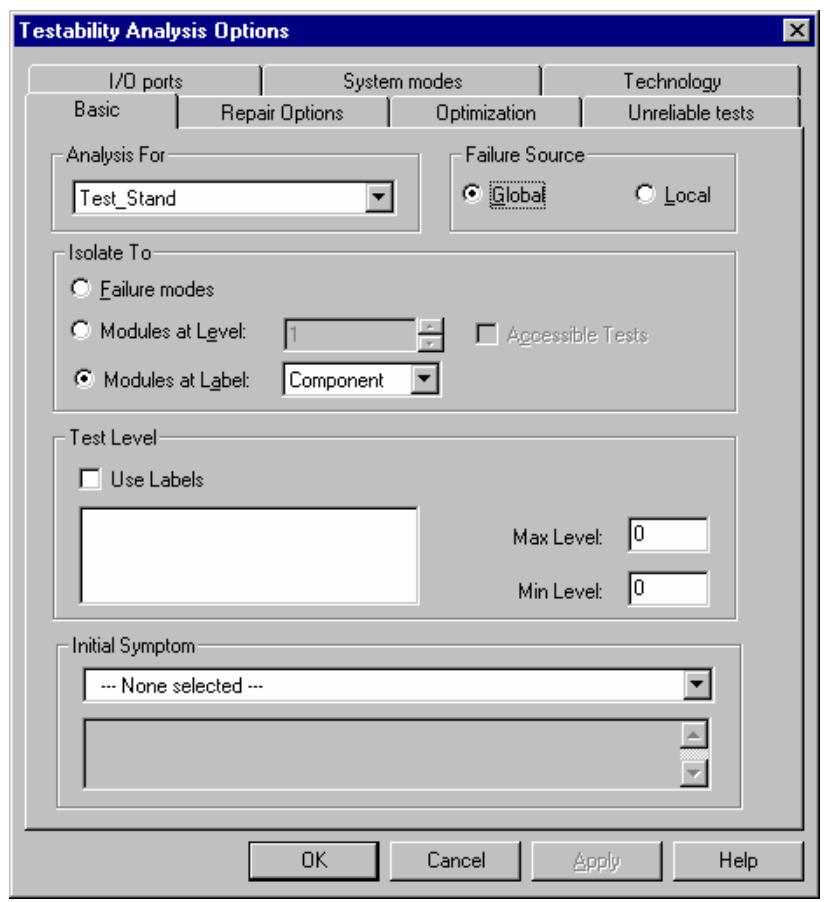

Fig.14 TEAMS Switch Property Control Panel

Although our initial objective was a proof-of-concept for diagnostic modeling of the test stand, i.e., to gain an understanding how the system functions and how it fails, meeting the needs of the operators and designers, understanding the system drawings and component functionality, along with learning the system's technical terminology, the more essential objective was to develop an accurate baseline model for performing what if trade study analyses, allow future changes and updates, and overall system improvements, the ultimate goal for modeling the test stand is to give the system designers a method that will add confidence by retrieving accurate verifiable test stand output data during test runs. Our effort here also is to illustrate with a completed test stand model that this technology is a reliable and valuable resource for modeling other vehicle systems. 


\section{TESTABILITY METRICS AND RESULTS}

The testability metrics here were chosen to reflect the immediate needs of the test stand users. They are also chosen to establish some baseline modeling metrics for future trade studies and other IVHM analysis and optimization applications.

The following Table 1 has the testability metrics for two different system operational modes (fill tanks and fuel engine feed). From the testability analysis, it can easily be seen here that the fault isolation with the current number of tests and placement of instrumentation is not adequate.
Notice the component failures are more isolatable than the functional failure modes, as one should expect, because the number of functional failures is much larger in number due to the fact that, a single component can perform multiple functions. In addition, the test stand instrumentation arrangement is causing the test instrument efficiency for isolating failures to be poor. This is also evident from the average ambiguity group sizes being too large. A good testability design can lower the failure ambiguity group sizes considerably and in some cases make the ambiguity group size a single component or single function, yielding one hundred percent fault isolation.

\begin{tabular}{|c|c|c|c|c|}
\hline & \multicolumn{4}{|c|}{ Test Stand System Operational Modes } \\
\hline & \multicolumn{2}{|c|}{ Rocket Engine Fuel Feed Mode } & \multicolumn{2}{|c|}{ Fuel Filling Tanks Mode } \\
\hline & $\begin{array}{c}\text { Component Failure } \\
\text { Mode }\end{array}$ & $\begin{array}{c}\text { Functional Failure } \\
\text { Mode }\end{array}$ & $\begin{array}{l}\text { Component Failure } \\
\text { Mode }\end{array}$ & $\begin{array}{c}\text { Functional Failure } \\
\text { Mode }\end{array}$ \\
\hline Fault detection $\%$ & $73.99 \%$ & $73.99 \%$ & $74.55 \%$ & $74.55 \%$ \\
\hline $\begin{array}{l}\text { Fault Isolation \% To } \\
\text { One Component }\end{array}$ & $32.40 \%$ & $6.24 \%$ & $31.26 \%$ & $6.21 \%$ \\
\hline $\begin{array}{l}\text { Average Ambiguity } \\
\text { Group Size }\end{array}$ & 40.05 & 78.67 & 38.57 & 75.88 \\
\hline MTTF & 31.02 hours & 31.02 hours & 31.02 hours & 31.02 hours \\
\hline $\begin{array}{l}\text { Efficiency of Test } \\
\text { Sequence }\end{array}$ & $8.54 \%$ & $8.56 \%$ & $8.68 \%$ & $8.72 \%$ \\
\hline $\begin{array}{l}\text { Number of Tests Not } \\
\text { Used }\end{array}$ & 120 & 67 & 117 & 62 \\
\hline Total Number of Tests & 669 & 669 & 669 & 669 \\
\hline $\begin{array}{l}\text { Total Number of } \\
\text { Components (failure } \\
\text { sources) }\end{array}$ & 684 & 684 & 684 & 684 \\
\hline $\begin{array}{l}\text { Total Number of } \\
\text { Failure Modes } \\
\text { (functional failures) }\end{array}$ & 1712 & 1712 & 1712 & 1712 \\
\hline
\end{tabular}

Table 1 Output Metrics of Two System Operations Modes (Fill Tanks and Fuel Engine Feed) 
In Fig. 15 below the testability figure of merit (TFOM)

chart displays the testability metrics used to develop the Output Metrics in Table 1 above

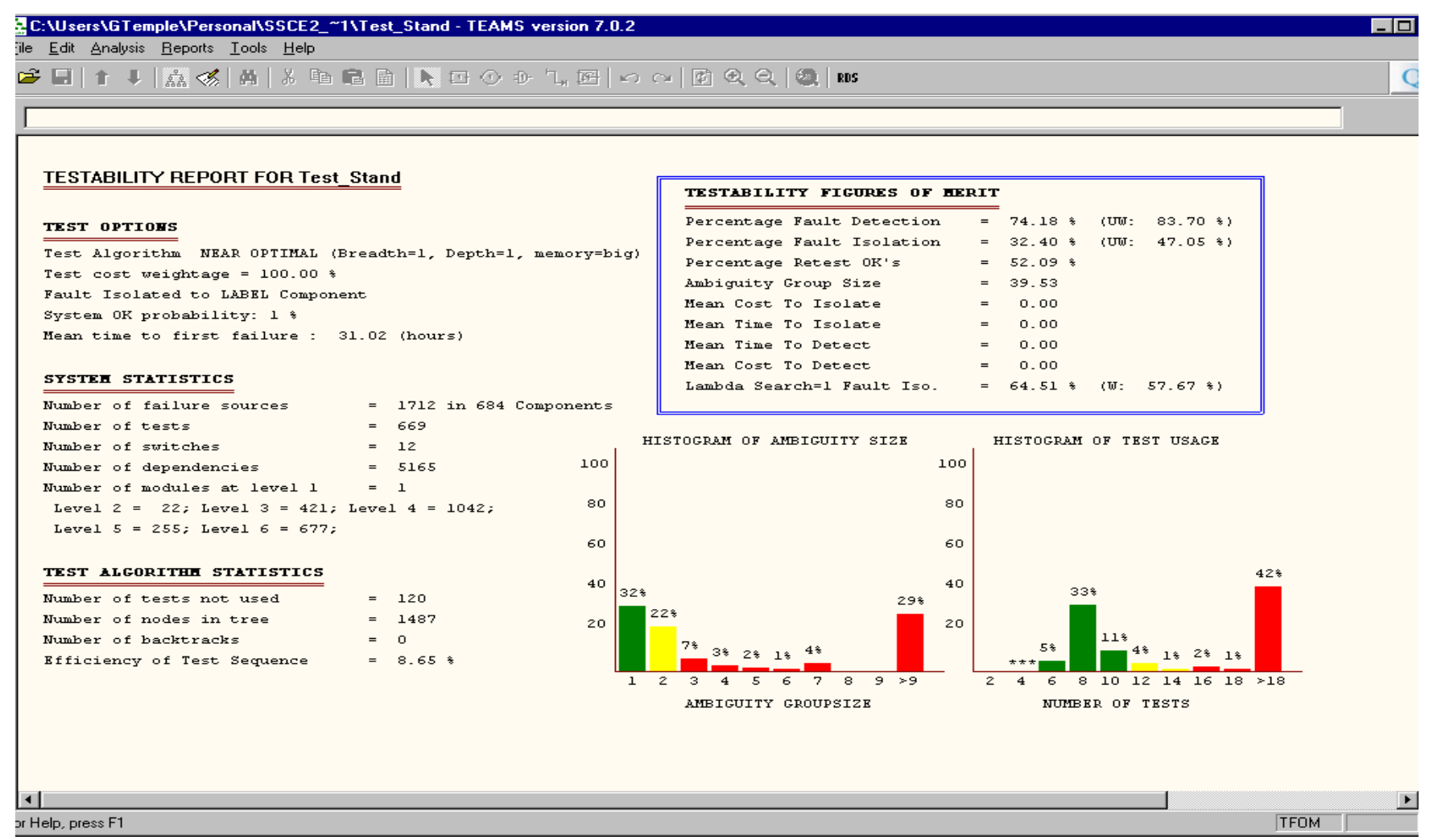

Fig.15 TFOM Chart of Output Metrics (Fill Tanks and Fuel Engine Feed)

Another useful output is the visualization of sensor(s) detecting a certain fault, or if the fault is seen or detected or covered by any sensors or instrumentation. Another useful feature of the testability analysis tool is the suggested placement of instruments to detect and isolate a particular fault. When a sensor is added, will it be effective in finding a critical fault (failure or failure mode)? The testability tool allows us to do that. In our model, we developed the failure modes in valve PVC-14A01-GN, located in the Medium Pressure subsystem, as seen in the next page in Fig. 16. 


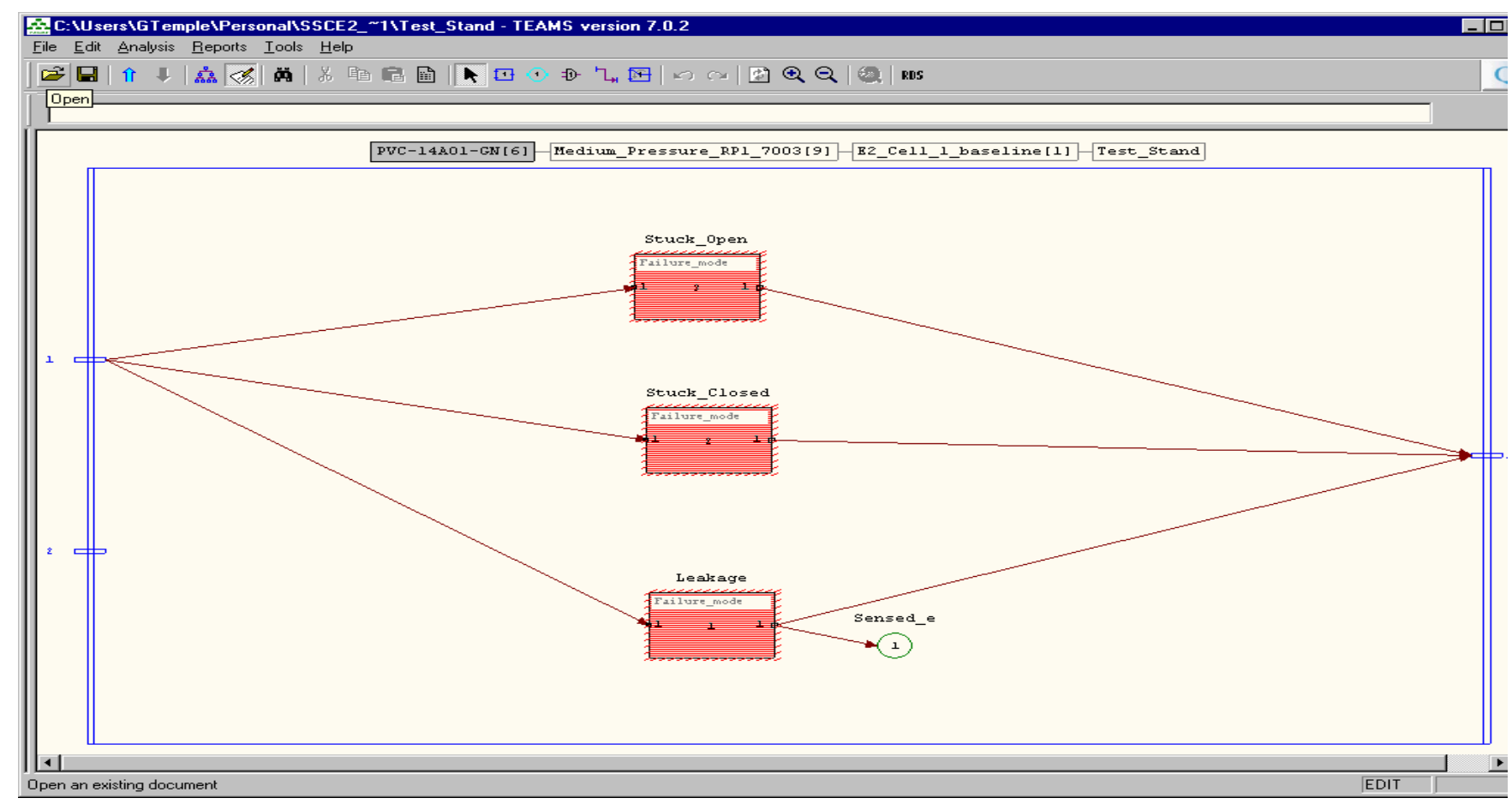

Fig 16 Valve PVC-14A01-GN Located in the Medium Pressure Subsystem

After running a simulation we selected a failure mode to see which sensors were detecting it, as seen here in Fig. 17.

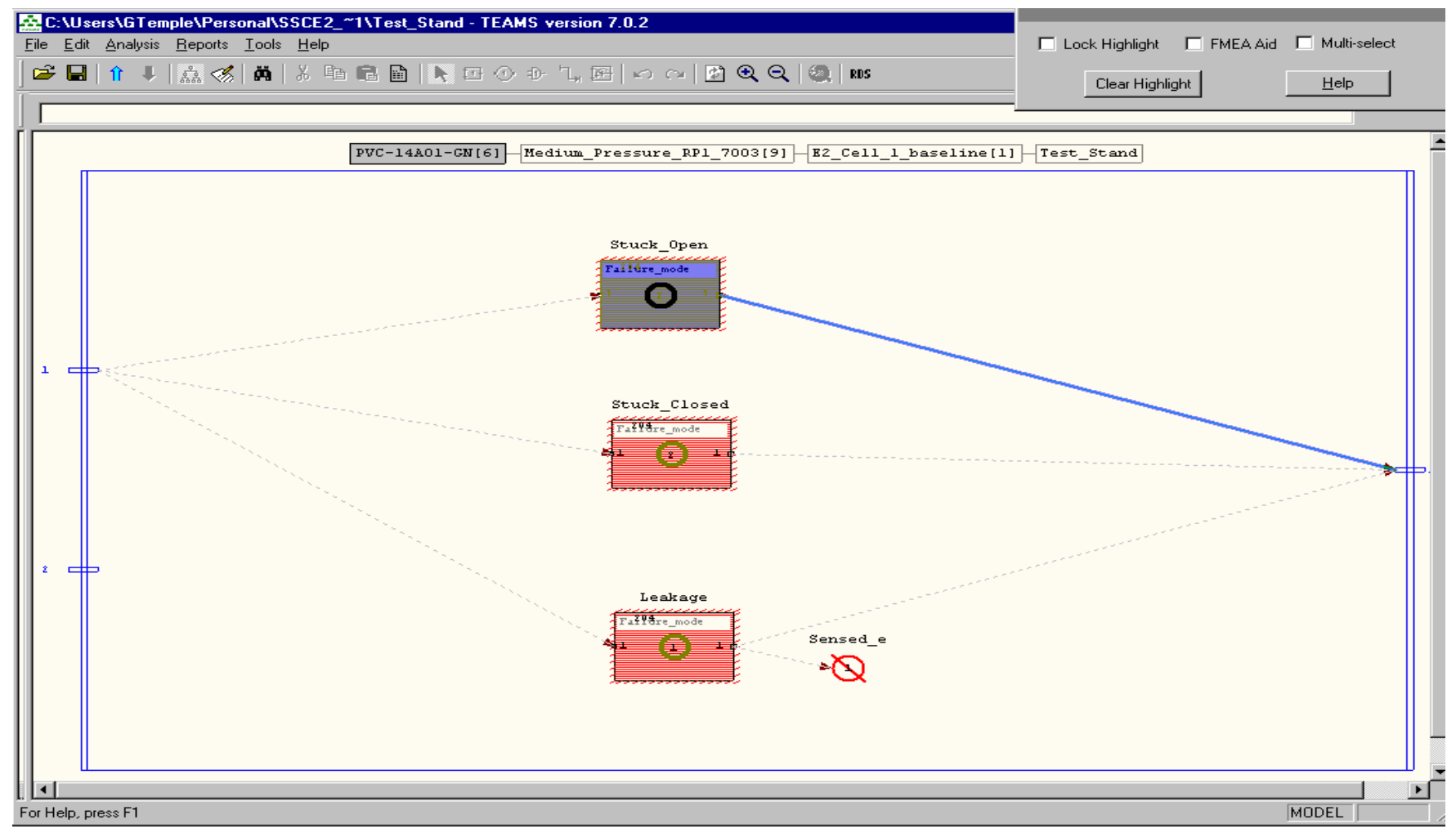

Fig.17 Valve PVC-14A01-GN Stuck Open 
When we go up one level higher in the test stand medium pressure RP1 fill tank model hierarchy seen in Fig. 18, we can see that two tests (sensors modeled), highlighted in green, detect the valve failure (stuck open fault mode). Therefore, one can answer questions such as the following: will the technicians see the test stand instrumentation sensors and relate the readings to a particular ambiguity group? This can also be done while the test stand is operating and taking data using the real time inference tool in the TEAMS toolset, the TEAMS-RT tool

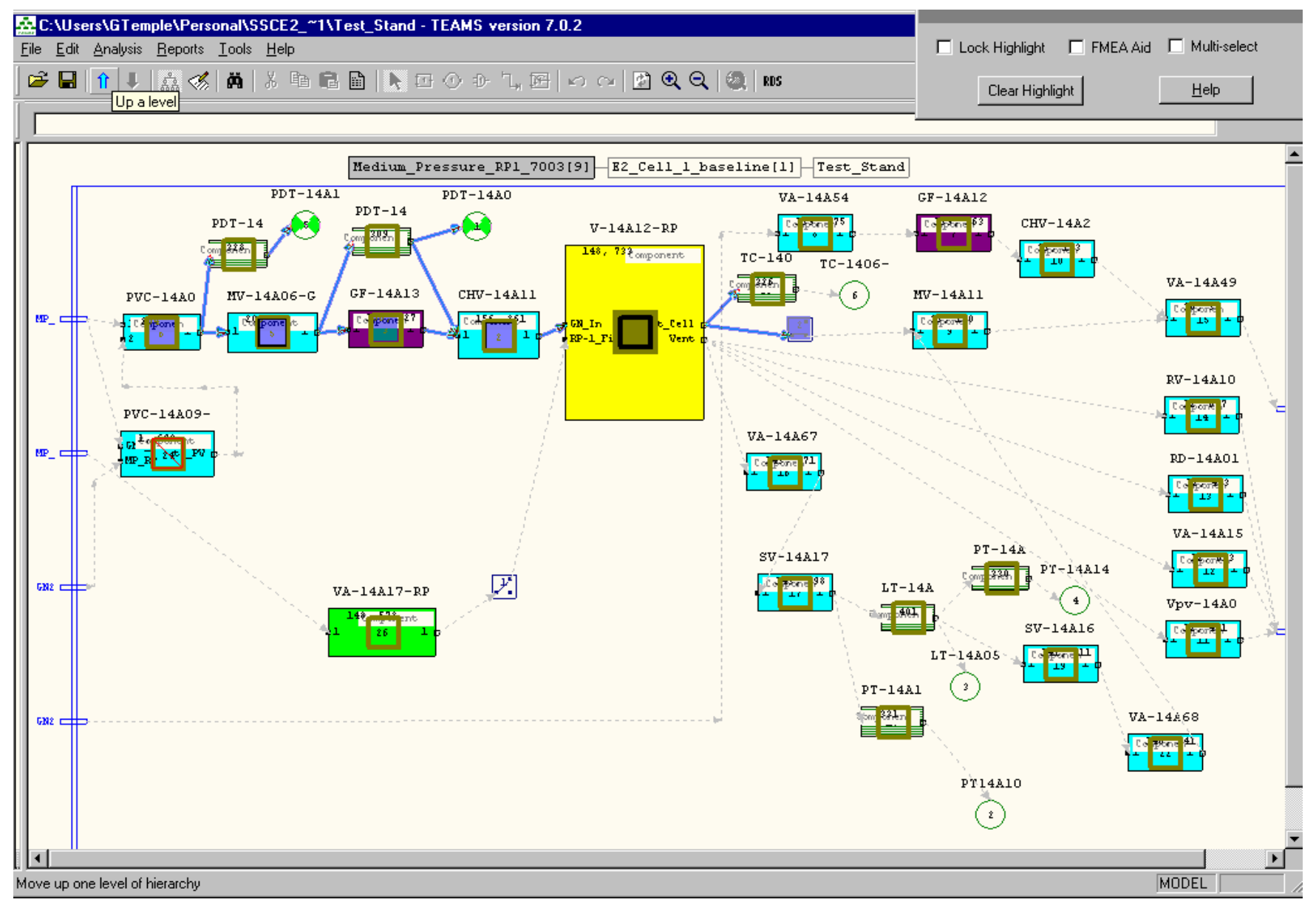

Fig.18 Valve PVC-14A01-GN Stuck Open

\section{CONCLUSIONS}

The test stand presently detects component faults and functional failures using a data acquisition computer that monitors many instrumented components and human observations. One of the limitations of this method is that it results in a large number of false failure analyses, false alarms, and false replacements. Testability analysis tools are much more precise and could eliminate many of these false failure indications. The present test stand computers and human observations show whether a functional failure has occurred, and if so, where and when it is occurring, or has occurred. Testability analysis can illustrate during the design stage, prior to turn on, as well as during operation, which sensors can catch or detect faults and the associated ambiguity groups, or if a given sensor can isolate a particular failure to a given component. This allows the test stand engineers to not just target a component that has failed. If there is failure ambiguity, the testability tool will suggest the most likely cause, and guide the technician to resolve the problem in minimum time and/or cost. Also, when multiple faults occur simultaneously, analysis via realtime inference tools, such as TEAMS-RT will be a great deal more accurate and useful than manual troubleshooting 
The following quantifiers, top-level figures of merit, are resolved as measurable using the resultant testability model simulation metrics

System Autonomy - can be measured as a percentage of improvement. It is a result testability analysis being computerized and a function of the kind of hardware that is used, such the implementation of the latest technologies available, e.g. the IEEE 1451 bus standard and associated STIM (Smart Transducer Interface Modules), TEDS (Transducer Electronic Data Sheets).

Overall System Efficiency - can be much better because the automated system removes a great deal of the human element, and computer monitoring only, from doing fault isolation and detection and also gives ambiguity group measurement and location. The test efficiency metric of $8.65 \%$ from our analysis illustrates the measure of the test stand instrumentation suite design.

Safety and Reliability - probability of success; can be based on the system failure rate, or the MTTF. 31.02 hours is the MTTF testability model output metric for the test stand.

Maintainability - the time the system is down for repair or amount of down time per total operating time and maintenance time. Autonomous fault detection and fault isolation are the testability metrics that will improve this. The average ambiguity size of 39.53 components is a metric that can be improved upon significantly to improve maintainability of the test stand.

Availability - the operational up time per total operating and maintenance time. Autonomous fault detection and fault isolation are the testability metrics that will improve this. After looking at about 100 test stand historical maintenance records called DR's (Discrepancy Reports) and noting the date of the incident and the date of repair completion, an average MTTR (Mean Time To Repair or Replace) was estimated to be about 80 hours. This figure includes scheduled maintenance as well as condition-based maintenance. We don't have enough data to give an accurate percentage of how much the MTTR can be improved. (This is actually the test time that is gotten from the TFOMs. If one had specified the test times and repair time, one can get this metric.

Sustainability - the probability of survival after repairs measures how much maintainability will increase operating time before the next maintenance action is needed. This metric is TBD.

Maintenance Costs Reduction - The Maximizing Fault Isolation., minimizing the ambiguity group sizes and minimizing the mean time to troubleshoot and repair (MTTR) are metrics that will improve this.
Critical Components Identification - comes from expert information with the corresponding failure modes of those components or functions having weighted inputs to the test stand testability analysis model. We noted some components were safety critical from the DRs; but we did not include criticality weightings on components in our model.

A number of other factors create gaps for achieving model fidelity, such as interpretation of testability simulation output data. Simulation output charts, explanations and testability terminology can be difficult for others outside the testability arena to understand. To close these gaps and minimize problems of this sort, a testability dictionary that could be understood by laymen was created to reduce confusion and improve upon the communicative dialogue between the test engineers and, the system designers and system operators.

There are some inaccuracies in the model. A model of this size and complexity will almost always have some associated error percentage. It was our intent here to minimize the number of errors and create a model that was good enough to be used as a test bed for trade studies, future updates and refinements as needed. It is evident that more sensors/instrumentation tests and better placement of sensors are needed to improve the FD, FI, AGS, etc. What is not obvious is how much! The testability analysis tools give us the capability to optimize the quantity and placement of the required sensors against costs and other possible constraints, such as the weight of sensors added and improvements in the quality of the test stand customer's data retrieval. 


\section{ACRONYMS AND ABBREVIATIONS}$$
-\mathbf{A}-
$$

ALS Advanced Launch System

ANSI American National Standards Institute

ASME American Society of Mechanical Engineers

ASRM Advanced Solid Rocket Motor

A-TCC "A" Test Control Center

ATM Asynchronous Transfer Mode

AWS American Welding Society
\end{abstract}

B-TCC "B" Test Control Center

\begin{tabular}{ll} 
& \multicolumn{1}{c}{$-\mathbf{C}-$} \\
CADD & Computer Aided Design and Drafting \\
CCTV & Closed Circuit Television \\
CD & Compact Disk \\
CEF & Central Engineering File \\
CNC & Computer Numerical Control \\
C of F & Construction of Facilities \\
CS & Control System \\
CTF & Component Test Facility \\
CW & Cooling Water \\
& \\
& \\
DAF & Data Acquisition Facility \\
DAS & Data Acquisition System \\
DAT & Data Tape Format \\
DC & Direct Current \\
DI & De-ionized \\
DCAA & Defense Contract Audit Agency \\
DO & Dissolved Oxygen \\
DVOM & Digtal Voltage Ohm Meter
\end{tabular}

DVOM Digital Voltage Ohm Meter

\begin{tabular}{ll} 
EEB & \multicolumn{1}{c}{$-\mathbf{E}-$} \\
EPA & Electrical Equipment Building \\
& \\
FAR & Federal Acquisition Regulations \\
FCPF & Fluid Component Processing Facility \\
FFT & Fast Fourier Transform \\
FOS & Facility Operating Services \\
FMS & Flow Measurement System \\
FRS & Financial Reporting System \\
FTIR & Fourier Transform Infrared
\end{tabular}

$\begin{array}{ll}\text { GH2 } & \text { Gaseous Hydrogen } \\ \text { GHe } & \text { Gaseous Helium } \\ \text { GC } & \text { Gas Chromatograph }\end{array}$

GMAL Gas and Material Analysis Laboratory

GN2 Gaseous Nitrogen

GOX Gaseous Hydrogen

GPM Gallons per Minute

GSA General Services Administration

GTAW Gas Tungsten Arc Welding

\begin{tabular}{ll} 
& \multicolumn{1}{c}{$-\mathbf{H}-$} \\
HF & High Frequency \\
HHFF & High Heat Flux Facility \\
H2O & Water \\
H2O2 & Hydrogen Peroxide \\
HP & High-Pressure (3,000 psi to 8,000 psi) \\
HPA & High-Pressure Air \\
HPGF & High-Pressure Gas Facility \\
HPIW & High-Pressure Industrial Water \\
HSDAS High Speed Data Acquisition System \\
HTDP & Hybrid Technology Demonstration Program \\
HVAC & Heating, Ventilating, and Air Conditioning
\end{tabular}

$\begin{array}{ll}\text { I/O } & \text { Input/Output } \\ \text { IRIG } & \text { Time standard accurate to } 1 \mathrm{~ms} \\ & \\ \text { JP } & \text { Jet Propellant } \\ \text { LAN } & \text { Local Area Network } \\ \text { LH2 } & \text { Liquid Hydrogen } \\ \text { LN2 } & \text { Liquid Nitrogen } \\ \text { LOX } & \text { Liquid Oxygen } \\ \text { LP } & \text { Low Pressure } \\ \text { LSDAS Low Speed Data Acquisition System }\end{array}$

$$
-\mathbf{M}-
$$

MASS Management Accounting Statusing System MAWP Maximum Allowable Working Pressure

MCC Motor Control Center

MDWP Maximum Design Working Pressure

MP Medium Pressure (1,000 psi to 3,000 psi)

MPTA Main Propulsion Test Article

MV Motor Valve

$$
-\mathbf{N}-
$$

NASA National Aeronautics and Space Administration

NASP National Aero-Space Plane

NDTE Nondestructive Testing and Evaluation

NIST National Institute of Standards and Technology

NLS National Launch System

NVR Nonvolatile Residue

$$
-\mathbf{O}-\mathbf{P}-
$$

ODIN Outsourcing Desktop Initiative for NASA

PC Personal Computer

PER Preliminary Engineering Report

PLC Programmable Logic Controller

PM Preventive Maintenance

PM/CM Preventive and/or Corrective Maintenance

PRA Pressure Reducing Area

PSCS Program Support Computer System

$\begin{array}{ll}\text { RF } & \text { Radio Frequency } \\ \text { ROM } & \text { Read-Only Memory }\end{array}$


RP Rocket Propellant

RTD Resistance Temperature Detector

SCB Signal-Conditioning Building

SCFM Standard Cubic Foot per Minute

SDS Stennis Desktop Services

SEM Scanning Electron Microscope

SSC John C. Stennis Space Center

SSME Space Shuttle Main Engine

STD Standard

STE Special Test Equipment

STS Space Transportation System

SVHS Super VHS

\begin{tabular}{ll} 
& \multicolumn{1}{c}{$-\mathbf{T}-$} \\
TCC & Test Control Center \\
TCP/IP & Telecommunication Control Program/Input \\
TEA & Triethyl-Aluminum \\
TEB & Triethyl-Borane \\
TMS & Thrust Measurement System \\
TOB & Test Operations Building \\
TTSC & Test \& Technical Support Contractor
\end{tabular}

$\begin{array}{ll}\text { UHP } & \text { Ultrahigh Pressure } \\ \text { UPS } & \text { Uninterruptible Power Sup } \\ & \\ \text { VAC } & \text { Volts Alternating Current } \\ \text { VDC } & \text { Volts Direct Current } \\ \text { VJ } & \text { Vacuum Jacketed } \\ \text { VP } & \text { Valve P }\end{array}$

\section{ABBREVIATIONS}

${ }^{\circ} \mathrm{C}$ degree Celsius

${ }^{\circ} \mathrm{F}$ degree Fahrenheit

$\mu \quad$ micron (micrometer)

$\mu \mathrm{A}$ microampere

$\mu$ in microinch

$\mu \mathrm{s} \quad$ microsecond

$\mu \mathrm{V} / \mathrm{D}$ microvolt/division

A ampere

ac alternating current

$\mathrm{CO}$ carbon monoxide

$\mathrm{CO} 2$ carbon dioxide

$\mathrm{dB}$ decibel

dc direct current

$\mathrm{ft}$ feet

$\mathrm{ft} 2$ square feet

$\mathrm{ft} 3$ cubic feet

$\mathrm{ft} 3 / \mathrm{hr} \quad$ cubic feet per hour

$\mathrm{ft}-\mathrm{lb}$ foot-pound

$\mathrm{ft} 3 /$ min cubic feet per min

gal gallon

$\mathrm{gal} / \mathrm{min}$ gallons per minute

Gbyte gigabyte

GH2 gaseous hydrogen

\begin{tabular}{|c|c|}
\hline $\mathrm{GHe}$ & gaseous helium \\
\hline $\mathrm{GHz}$ & gigahertz \\
\hline GN2 & gaseous nitrogen \\
\hline Gohm & gigohm \\
\hline GOX & gaseous oxygen \\
\hline $\mathrm{H} 2$ & hydrogen \\
\hline $\mathrm{H} 202$ & Hydrogen Peroxide \\
\hline $\mathrm{He}$ & helium \\
\hline $\mathrm{hp}$ & horsepower \\
\hline $\mathrm{Hg}$ & mercury \\
\hline $\mathrm{hr}$ & hour \\
\hline $\mathrm{Hz}$ & hertz \\
\hline in. & inch \\
\hline $\mathrm{kHz}$ & kilohertz \\
\hline ksps & kilo samples per second \\
\hline $\mathrm{kV}$ & kilovolt \\
\hline $\mathrm{kVA}$ & kilovoltampere \\
\hline $\mathrm{kW}$ & kilowatt \\
\hline $\mathrm{L}$ & liter \\
\hline $\mathrm{lb}$ & pound \\
\hline $\mathrm{lbf}$ & pounds force \\
\hline $\mathrm{lbm}$ & pounds mass \\
\hline $\mathrm{lb} / \mathrm{hr}$ & pounds per hour \\
\hline LH2 & liquid hydrogen \\
\hline LHe & liquid helium \\
\hline LN2 & liquid nitrogen \\
\hline LOX & liquid oxygen \\
\hline M & million \\
\hline M-lb & million pound \\
\hline $\mathrm{m} / \mathrm{s}$ & meters per second \\
\hline Mbyte & megabyte \\
\hline Mbyte/s & megabyte per second \\
\hline $\mathrm{mi}$ & mile \\
\hline $\min$ & minute \\
\hline $\mathrm{mm}$ & millimeter \\
\hline Mohm & megohm \\
\hline $\mathrm{ms}$ & millisecond \\
\hline MVA & megavoltampere \\
\hline $\mathrm{N} 2$ & nitrogen \\
\hline ns & nanosecond \\
\hline $\mathrm{ppb}$ & parts per billion \\
\hline $\mathrm{ppm}$ & parts per million \\
\hline psi & pounds per square inch \\
\hline psig & pounds per square inch gauge \\
\hline RP-1 & rocket propellant 1 \\
\hline $\mathrm{rpm}$ & revolutions per minute \\
\hline $\mathrm{s}, \mathrm{sec}$ & second \\
\hline $\operatorname{scf}$ & standard cubic feet \\
\hline $\operatorname{scfm}$ & standard cubic feet per minute \\
\hline sps & samples per second \\
\hline $\mathrm{V}$ & volt \\
\hline Vac & volts alternating current \\
\hline Vdc & volts direct current \\
\hline wk & week \\
\hline
\end{tabular}




\section{REFERENCES}

SSC Test Facilities Capability Handbook

TEAMS Users Guide

eXpress Users Guide

MIL-STD-1629A, Procedures for Performing Failure Mode

Effects and Criticality Analysis

MIL- HDBK-1814 Appendix D, Integrated Diagnostics

MIL-HDBK-2165, Testability Handbook

MIL-HDBK-781A, Reliability Test Methods, Plans, and Environments Reliability analysis Center

MIL-STD-471, Maintainability, Verification,

Demonstration Evaluation

MIL-STD-472, Maintainability Prediction

MIL-STD-1309, Definitions of Terms For Testing,

Measurement and Diagnostics

\section{ACKNOWLEDGMENTS}

The authors would like to gratefully acknowledge Fernando Figueroa for allowing us the opportunity to demonstrate the capability of the testability analysis technology on the Stennis Rocket Engine Test Stand. Also, we want to acknowledge his team of engineers for providing the technical information needed. The authors also acknowledge the consultation provided by Koushik Datta, Dave Squires, Dougal Maclise, Thomas Gormley and Scott Poll of NASA Ames Research Center, Charles Domagala, and Somnath Deb of Qualtech Systems (QSI), Daniel Hartop and Eric Gould of Detex Systems (DSI), and Dave Cheuvront of Johnson Space Flight Center. The authors gratefully acknowledge the work done by Russell Roberson and Farid Haddad of NASA Ames Research Center.

\section{BIOGRAPHIES}

Gerald Temple is an electronics instrumentation systems design and development engineer. He has a Bachelor of Science Degree in Electronics Engineering and is a Registered Professional Engineer. $\mathrm{He}$ has developed testability models for the IVHM Systems Engineering Team at NASA Ames Research Center for the past five years. He was instrumental in the successful development of the Systems Analysis and Optimization Process demonstrated at NASA Ames Research Center.

Nicholas N. Jize is the technical lead for the Integrated Vehicle Health Management (IVHM) systems engineering team. His knowledge of Reliability-Centered Maintenance and Condition-Based Maintenance was used to develop the maintenance philosophy modeling for the A \& O process. Nick also has experience in mechanical design and systems design that were also used to provide guidance in the development of the process. Nick earned a master's degree in engineering from San Jose State University and an undergraduate degree in Mechanical Engineering from Wayne State University. He is a member of the Society of Maintenance and Reliability Professionals

Philip Wysocki is the lead system engineer for the Integrated Vehicle Health Management (IVHM) systems engineering team. He has extensive knowledge and background in model based programming and system design. He has developed and implemented model interfaces for Discreet Event Simulation and Design for Testability applications. Systems Analysis and Optimization Process demonstrated at NASA Ames Research Center Phil earned a Bachelor of Science Degree in Computer Science. 